\title{
IGF1 gene polymorphisms associated with diabetic retinopathy risk in Chinese Han population
}

\author{
Jian Zhang ${ }^{1}$, Xiao Chen ${ }^{2}$, Like Zhang ${ }^{2}$ and Yi Peng ${ }^{3}$ \\ ${ }^{1}$ Department of Endocrinology, Xingtai People's Hospital, Xingtai 054031, Hebei, China \\ ${ }^{2}$ Department of Medical Optometry, Ophthalmology Hospital, Xingtai 054001, Hebei, China \\ ${ }^{3}$ Department of Endocrinology, The First People's Hospital of Zhangjiakou, Zhangjiakou 075000, Hebei, China \\ Correspondence to: Xiao Chen, email: a3ihgdsg@yeah.net \\ Keywords: IGFI, diabetic retinopathy, $+2 d m$, haplotype, serum concentration \\ Received: March 04, $2017 \quad$ Accepted: June 18, $2017 \quad$ Published: September 28, 2017 \\ Copyright: Zhang et al. This is an open-access article distributed under the terms of the Creative Commons Attribution License 3.0 \\ (CC BY 3.0), which permits unrestricted use, distribution, and reproduction in any medium, provided the original author and source \\ are credited.
}

\section{ABSTRACT}

Objective: This study aimed to explore the association of insulin-like growth factor 1 gene (IGF1) polymorphisms with diabetic retinopathy (DR) in a Chinese Han population.

Methods: Polymerase chain reaction-restriction fragment length polymorphism (PCR-RFLP) was used for genotyping. Genotype frequencies were compared by chisquare test. Odds ratio (OR) with $95 \%$ confidence interval $(95 \% \mathrm{CI})$ was calculated to express the risk intensity of DR. Linkage disequilibrium between IGF1 polymorphisms was analyzed by Haploview. Serum IGF1 concentration was measured by enzymelinked immunosorbent assays (ELISA) and assessed by student's $t$ test.

Results: AG genotype of rs6218 and TT genotype of rs35767 were significantly associated with the elevated risk of DR ( $r s 6218$ : $O R=1.77, P=0.04$; rs35767: $O R=2.32$, $P=0.03$ ) and type II diabetes mellitus (T2DM) ( $r$ 6218: $O R=1.92, P=0.00$. rs35767: $O R=2.29, P=0.02)$. Only $T$ allele of rs35767 significantly increased the risk of $D R$ (OR=1.45, $P=0.04$ ), however, rs6218 (OR=1.92, $P=0.00)$, rs35767 (OR=0.02, $P=0.02)$ and $r s 5742612(O R=2.21, P=0.04)$ showed obvious association with T2DM. Haplotypes were only associated with T2DM, but not DR. Minor allele homozygote of rs35767 was obviously correlated with serum IGF1 level.

Conclusion: IGF1 rs6218 and rs35767 polymorphisms contribute to the risk of DR. IGF1 rs35767 polymorphism may participate in the regulation of serum IGF1 concentration in DR.

\section{INTRODUCTION}

Diabetic retinopathy (DR) is a serious microvascular complication of diabetes mellitus (DM). The disease is characterized by progressive retinal degeneration, representing a leading cause of blindness in adults [1-3]. According to epidemiological investigations, the prevalence of DM was 285 million in the world in 2010, over one third of cases had developed DR [4]. Almost all type I DM (T1DM) cases and over 60\% type II DM (T2DM) patients finally develop DR [5]. DR is also found to be associated with the elevated risk of some life-threatening diseases, such as stroke, heart failure and coronary artery disease (CAD) [6]. So, investigating the pathogenesis of DR and symptomatic treatments are necessary and urgent nowadays. Poor control of blood glucose, blood pressure, diabetes duration are the important risk factors of DR development and progression [7, 8]. However, some DM patients with optimum glycemic control still develop DR [9], suggesting individually genetic factors are crucial elements of DR occurrence.

Insulin-like growth factor 1 (IGF1) is an important growth factor associated with multiple biologucal systems, 
such as cell proliferation, differentiation, survival and maturation [10]. It is usually synthesized and secreted by liver cells and exerts function via binding to the specific receptor IGF1R [11]. In structure, IGF1 is highly homologous with pro-insulin, also including receptor. It is identified to contribute to the main pathways in the progression of DM complications by endocrine [12]. What's more, IGF1 is reported to be involved in the development of epiretinal membranes (ERMs) which are a layer of pathologic tissues and are very important pathological conditions for DR [13-15].

In recent years, single nucleotide polymorphism (SNP) has become an important mean of revealing the susceptibility of individuals to some diseases. IGF1 protein encoded gene, IGF1 is located on chromosome 12q22-23 [16] and consisted of 5 exons and 4 introns, including a number of SNPs [17, 18]. However, few studies referred to the association between IGF1 SNPs and DR occurrence. Therefore, in this study, our objective was to explore the role of IGFI polymorphisms in DR development in Chinese Han population and a total of four common SNPs in IGF1 were selected, including rs972936 and rs6218, rs35767 and rs5742612.

\section{RESULTS}

\section{Basic characteristics}

Demographic characteristics and clinical parameters of the study groups were summarized in Table 1. Age and gender distributions had no significant difference between DR, diabetic non-retinopathy (DNR) and healthy control groups $(P>0.05)$. Disease duration of DM was longer in DR patients than in DNR patients, despite the difference was not significant $(P=0.343)$. Body mass index (BMI), systolic blood pressure (SBP), diastolic blood pressure (DBP) had marginally significant difference in DR vs. Control and DR vs. DNR comparison respectively $(P<0.05)$. Fasting plasma glucose (FPG) had significantly higher level in DR patients than in controls $(P=0.008)$, but no significant difference existed between DR and DNR patients. Besides, we failed to find any significant difference of other demographic characteristics and biochemical measures, such as smoking, drinking, triglyceride (TG), total cholesterol (TC), high density lipoprotein (HDL), low density lipoprotein (LDL) $(P>0.05$ for all $)$.

\section{Genotype distribution of IGF1 polymorphisms in DR, DNR and healthy control groups}

Genotype frequencies of $I G F 1$ polymorphisms in DR, DNR and healthy control groups were displayed in Table 2. Genotype distributions of IGF1 polymorphisms were accorded with the HWE test in the control group. It demonstrated that the study subjects could present the same Mendelian population.
In our study, genotypes of rs972936 SNP had no significant difference between DR and DNR, DR+DNR and controls $(P>0.05)$. It suggested that rs972936 SNP was not associated with the risk of T2DM or DR occurrence. Heterozygous AG genotype of rs6218 was significantly associated with the elevated risk of DR development $(\mathrm{OR}=1.772,95 \% \mathrm{CI}=1.03-3.06)$, meanwhile, it was also a risk factor for occurrence of T2DM $(P=0.00, \mathrm{OR}=1.92$, $95 \% \mathrm{CI}=1.24-2.97)$. TT genotype of rs35767 carriers were significantly more in T2DM patients than that of the healthy controls $(P=0.02,16.80 \%$ vs. $9.15 \%)$, indicating it was a risk factor of T2DM $(\mathrm{OR}=2.29,95 \% \mathrm{CI}=1.13-4.68)$. Similarly, TT genotype frequency of rs35767 in DR group was obviously higher than that in DNR group $(P=0.03$, $21.74 \%$ vs. $12.40 \%$ ). So it could significantly increase the risk of DR development, compared with CC genotype $(\mathrm{OR}=2.32,95 \% \mathrm{CI}=1.07-5.03)$. We also found that $\mathrm{CC}$ genotype frequency of rs5742612 between T2DM patients and the controls was significant different $(P=0.04)$, but not DR or DNR $(P=0.13)$. It indicated that $\mathrm{CC}$ genotype was associated with $\mathrm{T} 2 \mathrm{DM}$ susceptibility $(\mathrm{OR}=2.21$, $95 \% \mathrm{CI}=1.01-4.80)$, but not DR.

\section{Allele distribution of IGF1 polymorphisms in DR, DNR and healthy control groups}

For allele of IGF1 polymorphisms (Table 3), we found that only $\mathrm{T}$ allele of rs35767 had significantly higher frequency in DR than that in DNR groups $(P=0.04,47.39 \%$ vs. 38.37). When compared with $\mathrm{C}$ allele (52.61\% vs. $61.63 \%)$, T allele might is a risk factor for DR occurrence $(\mathrm{OR}=1.45,95 \% \mathrm{CI}=1.01-2.08)$. But, alleles of rs972936, rs6218 and rs5742612 SNPs had no significant association with the DR susceptibility $(P>0.05)$. Meanwhile, we also failed to detect the association between rs972936 allele with DR or T2DM development $(P=0.57)$. IGF1 rs6218 $\mathrm{G}$ allele $(\mathrm{OR}=1.57,95 \% \mathrm{CI}=1.14-2.12)$, rs35767 $\mathrm{T}$ allele $(\mathrm{OR}=1.39,95 \% \mathrm{CI}=1.03-1.88)$ and $\mathrm{rs} 5742612 \mathrm{C}$ allele $(\mathrm{OR}=1.39,95 \% \mathrm{CI}=1.02-1.91)$ may obviously enhance the risk of T2DM development.

\section{Haplotype analysis between IGF1 polymorphisms in DR occurrence}

In the present study, the status of linkage disequilibrium in IGF1 polymorphisms was analyzed. Strong linkage disequilibrium was detected between rs972936 and rs6218, rs35767 and rs5742612 (Table 4). Three haplotypes were found in rs972936-rs6218, namely, C-A, T-A and T-G haplotypes. However, we could not found any haplotype which was associated with the risk of DR occurrence $(P>0.05)$. T-A $\quad(\mathrm{OR}=0.62,95 \% \mathrm{CI}=0.45-0.95)$ and $\mathrm{T}-\mathrm{G}$ $(\mathrm{OR}=1.42,95 \% \mathrm{CI}=1.02-1.98)$ haplotypes showed significant association with the susceptibility of T2DM occurrence, when compared with C-A haplotype. Strong linkage disequilibrium was also found between rs35767 and rs5742612. Only T-C 
Table 1: Baseline characteristics of participants

\begin{tabular}{|c|c|c|c|c|c|}
\hline Characteristic & DR $n=115(\%)$ & DNR $n=129(\%)$ & Control $n=142(\%)$ & $P 1$ & $P 2$ \\
\hline Age & $59.72 \pm 11.38$ & $59.05 \pm 10.88$ & $57.9 \pm 10.61$ & 0.235 & 0.264 \\
\hline Gender (male) & $49(42.61)$ & $54(41.86)$ & $57(40.14)$ & 0.689 & 0.906 \\
\hline $\begin{array}{l}\text { Duration of DM } \\
\text { (years) }\end{array}$ & $14.05 \pm 7.72$ & $13.98 \pm 8.67$ & - & - & 0.343 \\
\hline Smoking (yes) & $43(37.39)$ & $43(33.33)$ & $44(30.99)$ & 0.281 & 0.508 \\
\hline Drinking (yes) & $47(40.87)$ & $49(37.98)$ & $48(33.80)$ & 0.243 & 0.645 \\
\hline BMI $\left(\mathrm{Kg} / \mathrm{m}^{2}\right)$ & $22.3 \pm 6.8$ & $23.5 \pm 6.5$ & $24.5 \pm 6.3$ & 0.034 & 0.042 \\
\hline $\mathrm{SBP}(\mathrm{mmHg})$ & $140.6 \pm 20.25$ & $135.8 \pm 19.77$ & $127.6 \pm 19.42$ & 0.035 & 0.047 \\
\hline $\mathrm{DBP}(\mathrm{mmHg})$ & $81.72 \pm 12.39$ & $81.96 \pm 11.96$ & $79.81 \pm 11.90$ & 0.057 & 0.107 \\
\hline FPG $((\mathrm{mmol} / \mathrm{L})$ & $10.19 \pm 4.39$ & $8.43 \pm 3.57$ & $7.85 \pm 4.23$ & 0.008 & 0.098 \\
\hline $\mathrm{TG}(\mathrm{mmol} / \mathrm{L})$ & $1.59 \pm 1.12$ & $1.65 \pm 1.37$ & $1.61 \pm 1.23$ & 0.302 & 0.221 \\
\hline $\mathrm{TC}(\mathrm{mmol} / \mathrm{L})$ & $4.16 \pm 1.79$ & $3.87 \pm 1.86$ & $4.24 \pm 1.91$ & 0.351 & 0.168 \\
\hline HDL (mmol/L) & $1.14 \pm 0.64$ & $0.97 \pm 0.61$ & $1.16 \pm 0.52$ & 0.213 & 0.113 \\
\hline $\mathrm{LDL}(\mathrm{mmol} / \mathrm{L})$ & $2.22 \pm 1.31$ & $2.06 \pm 1.24$ & $2.19 \pm 1.27$ & 0.863 & 0.761 \\
\hline IGF1 (mg/dL) & $207.14 \pm 11.38$ & $173.43 \pm 12.04$ & $139.58 \pm 11.97$ & 0.004 & 0.007 \\
\hline
\end{tabular}

Notes: P1: DR vs. Control; P2: DR vs. DNR; BMI, body mass index; SBP, systolic blood pressure; DBP, diastolic blood pressure; FPG, fasting plasma glucose; TG, triglyceride; TC, total cholesterol; HDL, high density lipoprotein; LDL, low density lipoprotein; significant level was adjusted by Bonferroni method.

Table 2: The genotype distributions of $I G F 1$ polymorphisms in subjects

\begin{tabular}{|c|c|c|c|c|c|c|c|c|c|c|c|c|}
\hline \multicolumn{2}{|c|}{ Genotype } & \multicolumn{2}{|c|}{ DR } & \multicolumn{2}{|c|}{ DNR } & \multirow[t]{2}{*}{$P 1$} & \multirow[t]{2}{*}{ OR (95\%CI) } & \multicolumn{2}{|c|}{ Control } & \multirow[t]{2}{*}{$P_{\text {HWE }}$} & \multirow[t]{2}{*}{$P 2$} & \multirow[t]{2}{*}{ OR $(95 \% \mathrm{CI})$} \\
\hline & & $N=115$ & $\%$ & $\mathrm{~N}=129$ & $\%$ & & & $\mathrm{~N}=142$ & $\%$ & & & \\
\hline \multirow[t]{3}{*}{ rs972936 } & $\mathrm{CC}$ & 24 & 20.87 & 35 & 27.13 & - & Ref. & 37 & 26.06 & 0.07 & - & Ref. \\
\hline & $\mathrm{CT}$ & 65 & 56.52 & 73 & 56.59 & 0.41 & $1.30(0.70-2.41)$ & 81 & 57.04 & & 0.79 & $1.07(0.65-1.75)$ \\
\hline & $\mathrm{TT}$ & 26 & 22.61 & 21 & 16.28 & 0.13 & $1.81(0.83-3.92)$ & 24 & 16.90 & & 0.53 & $1.23(0.65-2.33)$ \\
\hline \multirow[t]{3}{*}{ rs 6218} & $\mathrm{AA}$ & 34 & 29.57 & 55 & 42.63 & - & Ref. & 75 & 52.82 & 0.62 & - & Ref. \\
\hline & $\mathrm{AG}$ & 69 & 60.00 & 63 & 48.84 & 0.04 & $1.77(1.03-3.06)$ & 58 & 40.84 & & 0.00 & $1.92(1.24-2.97)$ \\
\hline & GG & 12 & 10.43 & 11 & 8.53 & 0.23 & $1.77(0.70-4.44)$ & 9 & 6.34 & & 0.07 & $2.15(0.94-4.94)$ \\
\hline \multirow[t]{3}{*}{ rs35767 } & $\mathrm{CC}$ & 31 & 26.96 & 46 & 35.66 & - & Ref. & 56 & 39.44 & 0.12 & - & Ref. \\
\hline & $\mathrm{CT}$ & 59 & 51.30 & 67 & 51.94 & 0.36 & $1.31(0.74-2.32)$ & 73 & 51.41 & & 0.32 & $1.26(0.80-1.97)$ \\
\hline & $\mathrm{TT}$ & 25 & 21.74 & 16 & 12.40 & 0.03 & $2.32(1.07-5.03)$ & 13 & 9.15 & & 0.02 & $2.29(1.13-4.68)$ \\
\hline \multirow[t]{3}{*}{ rs5742612 } & $\mathrm{TT}$ & 41 & 35.65 & 56 & 43.41 & - & Ref. & Ref. & 48.59 & 0.39 & - & Ref. \\
\hline & $\mathrm{CT}$ & 56 & 48.70 & 60 & 46.51 & 0.38 & $1.28(0.74-2.19)$ & 63 & 44.37 & & 0.22 & $1.31(0.85-2.02)$ \\
\hline & $\mathrm{CC}$ & 18 & 15.65 & 13 & 10.08 & 0.13 & $1.89(0.83-4.29)$ & 10 & 7.04 & & 0.04 & $2.21(1.01-4.80)$ \\
\hline
\end{tabular}

Notes: P1: DR vs. DNR; P2: DR+DNR vs. Control.

haplotype was associated with the significantly increased risk of $\mathrm{T} 2 \mathrm{DM}(\mathrm{OR}=1.42,95 \% \mathrm{CI}=1.03-1.95)$, but any haplotypes of rs35767-rs5742612 did not associated with the susceptibility of DR development. 
Table 3: The allele distributions of IGF1 polymorphisms in subjects

\begin{tabular}{|c|c|c|c|c|c|c|c|c|c|c|c|}
\hline \multicolumn{2}{|c|}{ Genotype } & \multicolumn{2}{|c|}{ DR } & \multicolumn{2}{|c|}{ DNR } & \multirow[t]{2}{*}{$P 1$} & \multirow[t]{2}{*}{ OR $(95 \% \mathrm{CI})$} & \multicolumn{2}{|c|}{ Control } & \multirow[t]{2}{*}{$P 2$} & \multirow[t]{2}{*}{ OR $(95 \% C I)$} \\
\hline & & $N=115$ & $\%$ & $N=129$ & $\%$ & & & $\mathrm{~N}=142$ & $\%$ & & \\
\hline \multirow[t]{2}{*}{ rs972936 } & $\mathrm{C}$ & 113 & 49.13 & 143 & 55.43 & - & Ref. & 155 & 54.58 & - & Ref. \\
\hline & $\mathrm{T}$ & 117 & 50.87 & 115 & 44.57 & 0.16 & $1.29(0.90-1.84)$ & 129 & 45.42 & 0.57 & $1.09(0.81-1.46)$ \\
\hline \multirow[t]{2}{*}{ rs 6218} & A & 137 & 59.57 & 173 & 67.05 & - & Ref. & 208 & 73.24 & - & Ref. \\
\hline & G & 93 & 40.43 & 85 & 32.95 & 0.09 & $1.38(0.96-2.00)$ & 76 & 26.76 & 0.01 & $1.57(1.14-2.12)$ \\
\hline \multirow[t]{2}{*}{ rs35767 } & $\mathrm{C}$ & 121 & 52.61 & 159 & 61.63 & - & Ref. & 185 & 65.14 & - & Ref. \\
\hline & $\mathrm{T}$ & 109 & 47.39 & 99 & 38.37 & 0.04 & $1.45(1.01-2.08)$ & 99 & 34.86 & 0.03 & $1.39(1.03-1.88)$ \\
\hline \multirow[t]{2}{*}{ rs5742612 } & $\mathrm{T}$ & 138 & 60.00 & 172 & 66.67 & - & Ref. & 201 & 70.77 & - & Ref. \\
\hline & $\mathrm{C}$ & 92 & 40.00 & 86 & 33.33 & 0.13 & $1.33(0.92-1.93)$ & 83 & 29.23 & 0.04 & $1.39(1.02-1.91)$ \\
\hline
\end{tabular}

Notes: P1: DR vs. DNR; P2: DR+DNR vs. Control.

Table 4: The haplotype analysis between IGF1 polymorphisms in DR

\begin{tabular}{|c|c|c|c|c|c|c|c|c|c|c|}
\hline \multirow[t]{2}{*}{ Haplotype } & \multicolumn{2}{|c|}{ DR } & \multicolumn{2}{|c|}{ DNR } & \multirow[t]{2}{*}{$P 1$} & \multirow[t]{2}{*}{ OR $(95 \% C I)$} & \multicolumn{2}{|c|}{ Control } & \multirow[t]{2}{*}{$P 2$} & \multirow[t]{2}{*}{ OR $(95 \% \mathrm{CI})$} \\
\hline & $2 \mathrm{~N}=230$ & $\%$ & $2 N=258$ & $\%$ & & & $2 \mathrm{~N}=284$ & $\%$ & & \\
\hline \multicolumn{11}{|c|}{ rs972936-rs6218 } \\
\hline $\mathrm{C}-\mathrm{A}$ & 113 & 49.13 & 143 & 55.43 & - & Ref. & 155 & 54.58 & - & Ref. \\
\hline T-A & 24 & 10.43 & 30 & 11.63 & 0.97 & $1.01(0.56-1.83)$ & 53 & 18.66 & 0.03 & $0.62(0.40-0.95)$ \\
\hline T-G & 93 & 40.44 & 85 & 32.94 & 0.10 & $1.39(0.94-2.03)$ & 76 & 26.76 & 0.04 & $1.42(1.02-1.98)$ \\
\hline \multicolumn{11}{|c|}{ rs35767-rs5742612 } \\
\hline $\mathrm{C}-\mathrm{T}$ & 121 & 52.61 & 159 & 61.63 & - & Ref. & 185 & 65.14 & - & Ref. \\
\hline $\mathrm{T}-\mathrm{C}$ & 92 & 40.00 & 86 & 33.33 & 0.08 & $1.41(0.96-2.05)$ & 83 & 29.23 & 0.03 & $1.42(1.03-1.95)$ \\
\hline $\mathrm{T}-\mathrm{T}$ & 17 & 7.39 & 13 & 5.04 & 0.16 & $1.72(0.80-3.67)$ & 16 & 5.63 & 0.51 & $1.24(0.66-2.34)$ \\
\hline
\end{tabular}

Notes: P1: DR vs. DNR; P2: DR+DNR vs. Control.

\section{Influence of IGF1 polymorphisms on serum IGF 1 concentration}

For exploring the mechanism of $I G F 1$ polymorphisms in DR, we measured the influence of IGF1 polymorphisms on serum IGF1 concentration. Student's t test demonstrated that compared with healthy controls, DR and DCR exhibited significantly elevated serum levels of IGF1 $(P<0.01)$. Furthermore, serum concentration of IGF1 was obviously higher in DR than that in DCR $(P<0.01)$ (Table 1, Figure 1). In DR patients, TT genotypes of rs35767 carriers had significantly higher serum IGF1 concentration than that of $\mathrm{CC}$ and $\mathrm{CT}$ genotype carriers respectively $(P<0.01$ for both, Figure 2$)$. Serum IGF1 level was similar between $\mathrm{CC}$ and $\mathrm{CT}$ genotype carriers. In addition, serum IGF1 levels were similar between rs972936 CC, CT and TT genotypes. Similar results were observed in other two polymorphisms, that is, no significant difference of serum IGF1 concentration was found between any two genotypes of rs6218 or rs5742612 polymorphisms (Figure 2).

\section{DISCUSSION}

Genetic factors play important roles in etiology of DR. SNP technology may be a promising approach to identify the susceptible population for DR, thus contributing to prevention and treatment of the disease. In the current study, we explored the genetic association of IGF1 polymorphisms with DR development in Chinese Han population, as well as the related mechanisms. The results showed that AG genotype of rs6218 was obviously associated with the increased risk of DR and T2DM occurrence. TT genotype of rs35767 might also be a risk factor for DR and T2DM. CC genotype of rs5742612 was only associated with the obviously increased risk of T2DM, but not DR. In allele distribution, only rs35767 T allele was significantly correlated with the elevated DR susceptibility and T2DM risk. G allele of rs6128 and C allele of rs5742612 only showed significant associations with increased susceptibility for T2DM occurrence, but not DR. The alleles and genotypes of rs972936 was not 
distinctly correlated with DR or T2DM. The present study might point out a novel approach for identification of high risk population of DR, which could help improve the prevention and management of DR.

The role of IGF1 polymorphisms in DR development had been reported in some populations. For example, in the study performed by Bazzaz et al., IGF1-383C/T and $-1089 \mathrm{C} / \mathrm{T}$ polymorphisms did not show significant association with DR susceptibility [12]. Uthra et al. investigated the role of cytosine-adenine (CA) $[17,18]$ repeats in IGF1 promoter region in DR development based on a Southern Indian cohort. The study showed that CA [18] repeats genotype was a risk factor of DR [19]. In this study, we found that rs35767 and rs6218 polymorphisms showed close association with risk of DR. In addition, strong linkage disequilibrium has been observed between rs972936 and rs6218, rs35767 and rs5742612. T-A and T-G haplotypes of rs972936-rs6128 were not related to DR susceptibility. However, the T-A haplotype might act as a protective factor and the T-G haplotype was a risk factor for T2DM. Similarly, T-C haplotype in rs35767-rs5742612 only contributed the risk of T2DM, but not DR susceptibility. Based on the data, we might reveal that the study polymorphisms might interact in the initiation and progression of DR.

Abnormal expression of IGF1 was observed in T2DM and DN cases, suggesting its functional roles in development and progression of the diseases [15, 20]. It was reported that IGF1 and glucose exposure could significantly promote migration and proliferation of retinal pigment epithelium in vitro [21]. In our study, we found that the expression patterns of IGF were significantly different among DR, DNR and the control groups, which was consistent with the previous investigations. In order to investigate the regulatory mechanisms of IGF1 polymorphisms in progression of DR, we measured the association of serum IGF1 concentration with the study polymorphisms in DR cases. Analysis results demonstrated that serum IGF1 concentration was significantly different between DR patients carrying TT, TC, CC genotypes of rs35767. Based on the data we speculated that rs35767 might influence DR susceptibility via altering the expression of $I G F 1$. However, we couldn't find the obvious difference of serum IGF1 concentration in different genotypes of rs972936, rs6218 and rs5742612 polymorphisms respectively. Given the strong linkage disequilibrium between rs35767 and rs5742612, we speculated that rs972936, rs6218 and rs5742612 polymorphisms might be involved in development of DR via influencing the allele frequencies of rs35767 polymorphisms. Besides, the variants in IGF1 gene might able to regulate the activity of IGF1 protein, thereby taking part in the development and progression of DR. However, this assumption need to be verified in the future studies.

Differently, Broniarczyk et al. found that rs35767, rs5742612 polymorphisms in promoter region of IGF1 didn't affect serum IGF1 level in children with growth disorders [22]. Kanbur and Sesti et al. reported that rs35767 was associated with changes of IGF1 level $[23,24]$. In the study which carried by Li et al., rs6218 in 3'UTR of IGF1 might regulate the transcriptional activity of $I G F 1$ mRNA

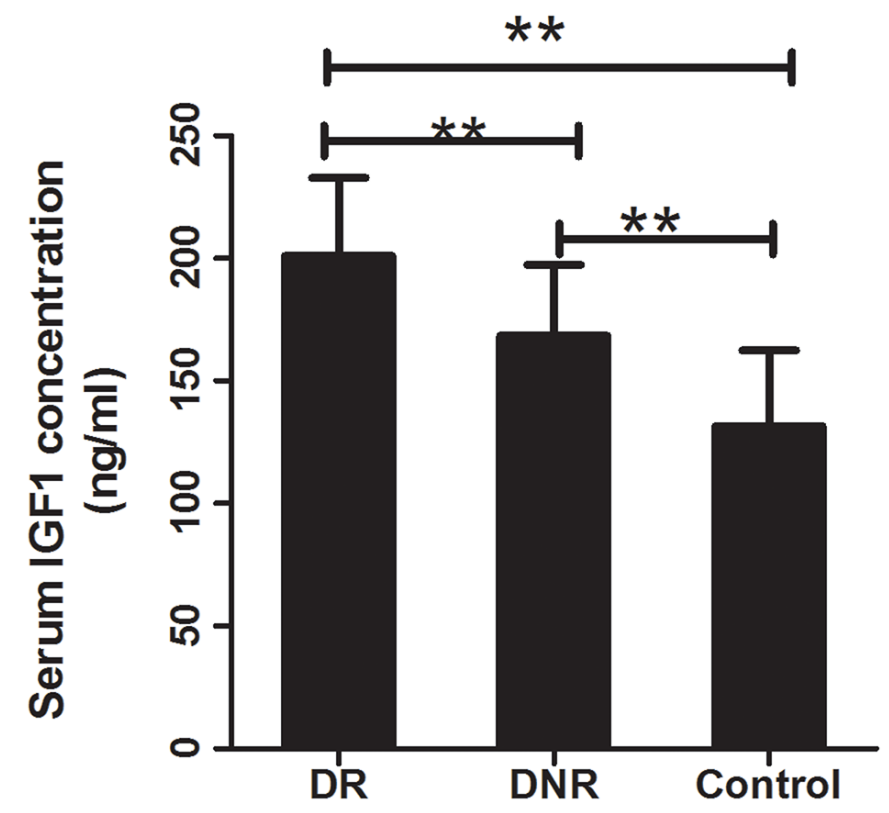

Figure 1: Serum concentration of IGF1 in DR, DNR and healthy control. Compared with the healthy controls, serum concentration of IGF1 was significantly increased in DR and DNR groups $(P<0.01$ for both). Moreover, DR exhibited obviously increased serum IGF1 concentration compared to the DNR group $(P<0.01)$. ${ }^{* *}$ : indicated $P<0.01$. 
level [25]. C allele of rs5742612 was also found to be associated with the increased circulating IGF1 level $[26,27]$. These inconsistent results may result from the influence of disease microenvironment on genotype distribution of polymorphisms, different study populations or sample size.
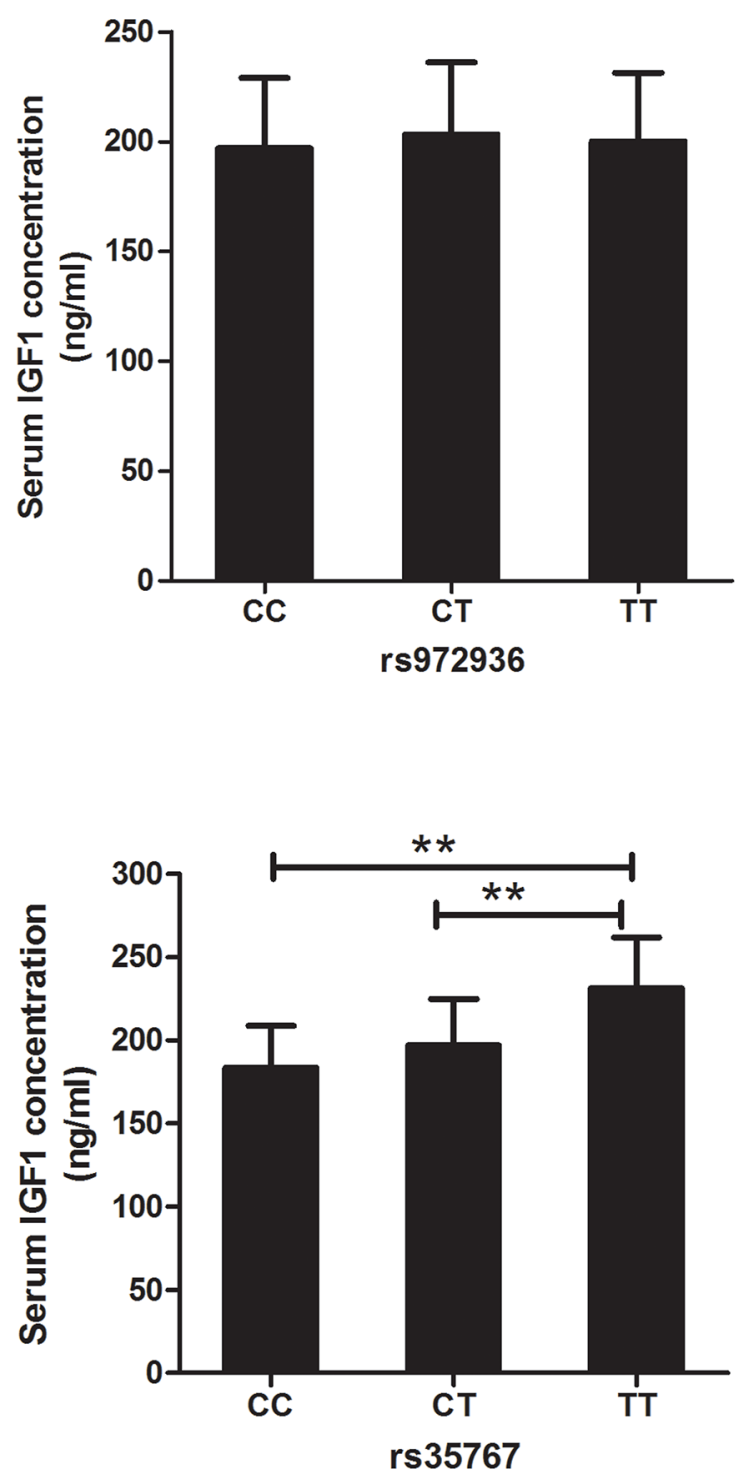

There were several limitations in the current research. First, the sample size was relatively small in the current study. Second, the results obtained in our study might be limited by the single population. In the current study, all the study subjects belonged to Chinese Han population. Third, environment factors and other
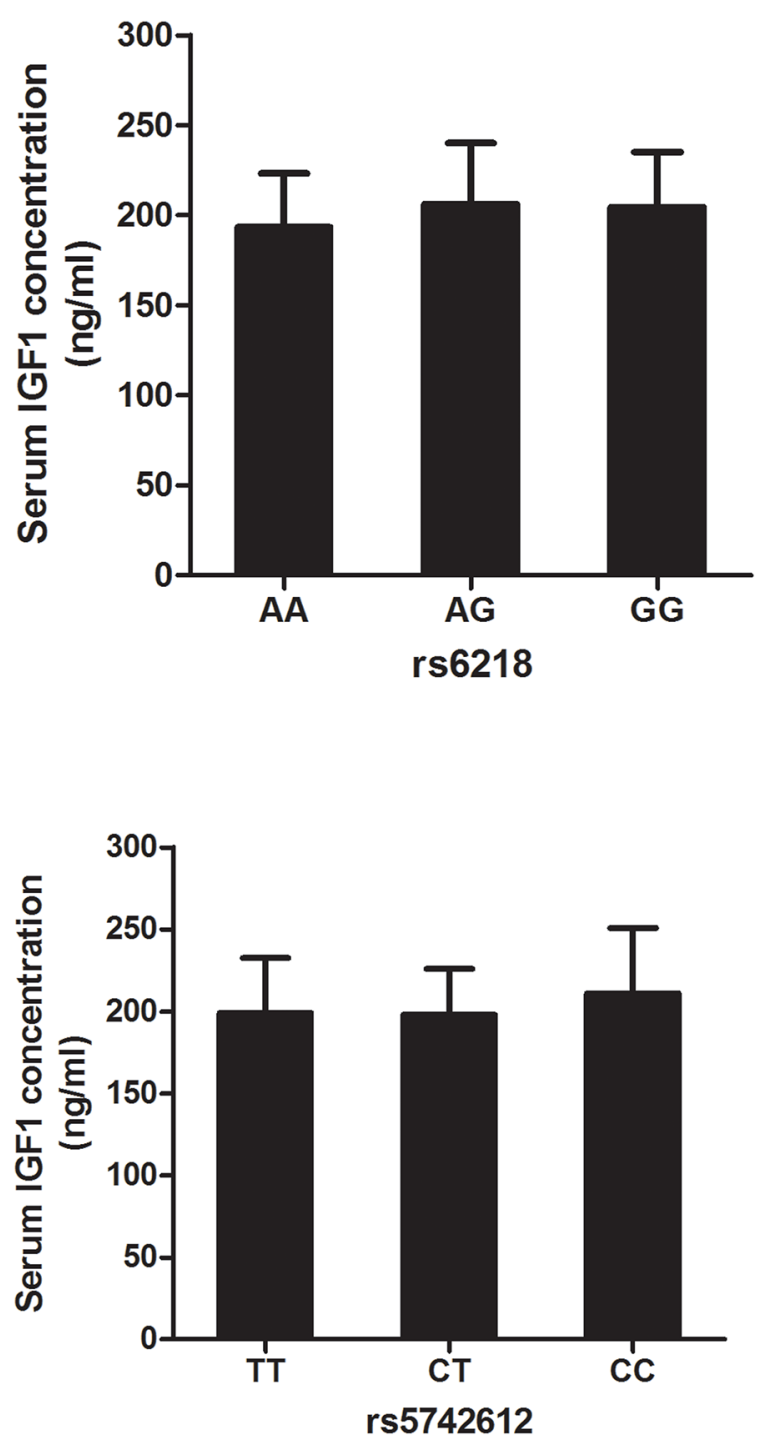

Figure 2: Association between IGF1 polymorphisms and serum IGF1 concentration in DR. Analysis result demonstrated that serum IGF1 concentrations didn't show significant difference between any two genotypes of rs972936, rs6218, or rs5742612 polymorphisms. Obvious higher serum IGF1 concentration was found in TT, compared with CT and CC genotypes carriers. Moreover, serum concentration of IGF1 was similar between CC and CT genotype carriers $(P=0.0748)$. ${ }^{* *}$ : suggested $P<0.01$. 


\begin{tabular}{llllc}
\hline & & Primer sequence & Position & Restriction enzyme \\
\hline rs972936 & For. & 5'GTTTGAGTCTTTTCAAGCGTTCA3' & Intron2 & Dra I \\
& Rev. & 5'ATCTGGGTTAGTCATCTGTGGCA3' & & \\
rs6218 & For. & 5'TCTGTGGAATAAGATACTGGACT3' & 3'UTR & Dra I \\
& Rev. & 5'ATCTAACTATGACAGAAAACACG3' & & \\
rs35767 & For. & 5'GAGCCAGAGTAGGATTTCAAGCA3' & Promoter & Hinf I \\
& Rev. & 5'CCAGAGCAGACATACCTCTTTCC3' & & \\
rs5742612 & For. & 5'AAAGTATGAGACAGTGCCCTAAA3' & Promoter & Ava I \\
& Rev. & 5'GGTAAAGTAGATTGGAAGACAGC3' & & \\
\hline
\end{tabular}

Note: 3'UTR: 3' untranslated region.

genetic factors did not considered in this study. Besides, present results did not adjusted by confounding factors. Additionally, we did not provide direct evidences for the regulatory mechanisms of IGF1 polymorphisms in DNR initiation. Animal models or cell experiments might be applied to investigate the related regulatory mechanisms. Further investigations were still required to address the above issues.

In conclusion, IGF1 rs6218 and rs35767 polymorphisms were significantly correlated to the occurrence risk of DR and T2DM, rs5742612 only influences the susceptibility to T2DM in this Chinese Han population. Rs35767 may participate in DR development through regulating serum IGF1 level, but not rs6218.

\section{MATERIALS AND METHODS}

\section{Participants}

In this study, a total of 244 type 2 diabetes mellitus (T2DM) patients (outpatients and inpatients) were recruited from the Department of Medical Optometry of Ophthalmology Hospital from 7, 2014 to 4, 2016, with the mean age of $59.6 \pm 11.3$ years. They were all confirmed as T2DM according to the diagnosis criteria of WHO (World Health Organization) in 1999, including 103 males and 141 females. Among them, 115 patients had developed DR and the rest 129 were diabetic nonretinopathy (DNR) cases. DR patients were diagnosed by professional eye doctor through the careful examination in eyes. The disease duration of all T2DM patients were over 5 years. The participants would be excluded if they suffered from known other types diabetes, thyroid dysfunction, chronic kidney disease, anemia, mental illness. Furthermore, the pregnant or breastfeeding women were also not permitted in this investigation [28]. 142 healthy controls who visited the hospital for physical examination were also recruited in this study, including 57 males and 85 females with the average age of $57.9 \pm 10.61$ years old. Healthy controls were matched with T2DM patients in age and gender. All participants were Chinese Han population without any blood relationship. This research was supported by the Ethics Committee of Ophthalmology Hospital. Before blood sample collection, written informed consents were signed by each participant.

\section{Sample collection and DNA extraction}

After fasting for $8-10 \mathrm{~h}, 2 \mathrm{ml}$ peripheral venous blood was collected from each participant in the early morning. The collected blood specimens were put in sterile and specified blood collection tube with EDTA, then plasma and leukocytes were isolated via centrifugation. The former was used to measure IGF1 concentration. Genomic DNA was extracted using TIANamp Genomic DNA Kit (TIANGEN BIOTECH (BEIJING) CO., LED), according to the manufacturer's instructions. Quality and concentration of DNA were detected by $1.0 \%$ agarose gel electrophoresis (AGE) and NanoDrop 2000c.

\section{Genotyping of IGF1 polymorphisms}

Polymerase chain reaction-restriction fragment length polymorphism (PCR-RFLP) was used for genotyping of $I G F 1$ polymophisms. PCR primers (Table 5) were designed by Primer Premier 5.0 software and synthesized in Sangon Biotech (Sangon, Shanghai). A volume of $25.0 \mu \mathrm{l}$ PCR system was used and PCR procedures were as follows: predenaturation at $95^{\circ} \mathrm{C}$ for $5 \mathrm{~min}, 30-35$ cycles with denaturation at $95^{\circ} \mathrm{C}$ for $30 \mathrm{~s}$, annealing at $56^{\circ} \mathrm{C}$ for $30 \mathrm{~s}$, extension at $72^{\circ} \mathrm{C}$ for $30 \mathrm{~s}$, and final extension at $72^{\circ} \mathrm{C}$ for $7 \mathrm{~min}$. PCR products were detected by $1.0 \%$ AGE.

Then PCR products were digested by specific restriction enzyme (Table 5). Enzyme-digested products were separated by $2.0 \%$ AGE. 


\section{Measurement of serum IGF1 concentration}

Serum IGF1 concentrations in DR, DNR and the healthy control groups were measured by enzyme-linked immunosorbent assays (ELISA) using Human IGF1 Elisa Kit (Shanghai Enzyme-linked Biotechnology Co., Ltd.). The operation procedures were according to the manufacturer's instruction. In the meanwhile, the differences of serum IGF1 concentrations were compared among different genotypes of $I G F 1$ polymorphisms.

\section{Statistical analysis}

Genotype frequencies of IGFI each polymorphism were gained by direct counting. Genotype distribution of polymorphisms in the healthy control groups was tested whether was consistent with Hardy-Weinberg equilibrium (HWE). Significant differences of genotype, allele frequencies were compared among groups by chi-square test. Furthermore, the status of linkage disequilibrium between IGF1 polymorphisms was examined by Haploview software. Odds ratio (OR) with corresponding $95 \%$ confidence interval $(95 \% \mathrm{CI})$ was calculated to express the association between the risk of DR and T2DM and genetic variants in IGF1. Continuous variables were presented by mean $\pm \mathrm{SD}$ and analyzed by student's $\mathrm{T}$ test. The statistical analysis was performed in SPSS 18.0 software. $P<0.05$ was considered as statistically significant.

\section{CONFLICTS OF INTEREST}

none

\section{REFERENCES}

1. Antonetti DA, Klein R, Gardner TW. Diabetic retinopathy. The New England journal of medicine. 2012; 366:1227-1239.

2. Dong L, Bai J, Jiang X, Yang MM, Zheng Y, Zhang H, Lin D. The gene polymorphisms of IL-8(-251T/A) and IP-10(-1596C/T) are associated with susceptibility and progression of type 2 diabetic retinopathy in northern Chinese population. Eye (Lond). 2017; 31:601-607.

3. Bourne RR, Stevens GA, White RA, Smith JL, Flaxman SR, Price H, Jonas JB, Keeffe J, Leasher J, Naidoo K, Pesudovs K, Resnikoff S, Taylor HR. Causes of vision loss worldwide, 1990-2010: a systematic analysis. The Lancet Global health. 2013; 1:e339-349.

4. Yau JW, Rogers SL, Kawasaki R, Lamoureux EL, Kowalski JW, Bek T, Chen SJ, Dekker JM, Fletcher A, Grauslund J, Haffner S, Hamman RF, Ikram MK, et al. Global prevalence and major risk factors of diabetic retinopathy. Diabetes care. 2012; 35:556-564.
5. Chen CF, Liou SW, Wu HH, Lin CH, Huang LS, Woung LC, Tsai CY. Regulatory SNPs Alter the Gene Expression of Diabetic Retinopathy Associated Secretary Factors. International journal of medical sciences. 2016; 13:717-723.

6. Cheung N, Mitchell P, Wong TY. Diabetic retinopathy. Lancet. 2010; 376:124-136.

7. Zorena K, Raczynska D, Raczynska K. Biomarkers in diabetic retinopathy and the therapeutic implications. Mediators of inflammation. 2013; 2013:193604.

8. Tarr JM, Kaul K, Chopra M, Kohner EM, Chibber R. Pathophysiology of diabetic retinopathy. ISRN ophthalmology. 2013; 2013:343560.

9. Sobrin L, Green T, Sim X, Jensen RA, Tai ES, Tay WT, Wang JJ, Mitchell P, Sandholm N, Liu Y, Hietala K, Iyengar SK, Brooks M, et al. Candidate gene association study for diabetic retinopathy in persons with type 2 diabetes: the Candidate gene Association Resource (CARe). Investigative ophthalmology \& visual science. 2011; 52:7593-7602.

10. Philippou A, Maridaki M, Pneumaticos S, Koutsilieris M. The complexity of the IGF1 gene splicing, posttranslational modification and bioactivity. Mol Med. 2014; 20:202-214.

11. Varewijck AJ, Janssen JA. Insulin and its analogues and their affinities for the IGF1 receptor. Endocrine-related cancer. 2012; 19:F63-75.

12. Bazzaz JT, Amoli MM, Taheri Z, Larijani B, Pravica V, Hutchinson IV. TGF-betal and IGF-I gene variations in type 1 diabetes microangiopathic complications. Journal of diabetes and metabolic disorders. 2014; 13:45.

13. Iannetti L, Accorinti M, Malagola R, Bozzoni-Pantaleoni F, Da Dalt S, Nicoletti F, Gradini R, Traficante A, Campanella M, Pivetti-Pezzi P. Role of the intravitreal growth factors in the pathogenesis of idiopathic epiretinal membrane. Investigative ophthalmology \& visual science. 2011; 52:5786-5789.

14. Bringmann A, Wiedemann P. Involvement of Muller glial cells in epiretinal membrane formation. Graefe's archive for clinical and experimental ophthalmology. 2009; 247:865-883.

15. Romaniuk D, Kimsa MW, Strzalka-Mrozik B, Kimsa MC, Kabiesz A, Romaniuk W, Mazurek U. Gene expression of IGF1, IGF1R, and IGFBP3 in epiretinal membranes of patients with proliferative diabetic retinopathy: preliminary study. Mediators of inflammation. 2013; 2013:986217.

16. Rotwein P, Pollock KM, Didier DK, Krivi GG. Organization and sequence of the human insulin-like growth factor I gene. Alternative RNA processing produces two insulin-like growth factor I precursor peptides. The Journal of biological chemistry. 1986; 261:4828-4832.

17. Zhang W, Zhang LC, Chen H, Tang PF, Zhang LH. Association between polymorphisms in insulin-like growth factor- 1 and risk of osteoporosis. Genetics and molecular research. 2015; 14:7655-7660. 
18. Rzehak P, Grote V, Lattka E, Weber M, Gruszfeld D, Socha P, Closa-Monasterolo R, Escribano J, Giovannini M, Verduci E, Goyens P, Martin F, Langhendries JP, et al. Associations of IGF-1 gene variants and milk protein intake with IGF-I concentrations in infants at age 6 months - results from a randomized clinical trial. Growth hormone \& IGF research. 2013; 23:149-158.

19. Uthra S, Raman R, Mukesh BN, Rajkumar SA, Kumari RP, Agarwal S, Paul PG, Lakshmipathy P, Gnanamoorthy P, Sharma T, McCarty CA, Kumaramanickavel G. Diabetic retinopathy and IGF-1 gene polymorphic cytosine-adenine repeats in a Southern Indian cohort. Ophthalmic research. 2007; 39:294-299.

20. Cander S, Oz Gul O, Dizdar OS, Koca N, Aydin T, Sarandol E, Ersoy C. Assessing the Impact of Insulin Glargine and Detemir Treatment to Serum Total IGF1 Levels in the Insulin-Naive Type 2 Diabetic Patients. Metabolic syndrome and related disorders. 2017; 15:220-225.

21. Spraul CW, Kaven C, Amann J, Lang GK, Lang GE. Effect of insulin-like growth factors 1 and 2, and glucose on the migration and proliferation of bovine retinal pigment epithelial cellsin vitro. Ophthalmic research. 2000; 32:244-248.

22. Broniarczyk JK, Kedzia A, Nowak W, Koscinski L, Lewandowski M, Gozdzicka-Jozefiak A. Polymorphisms in the P1 promoter of the IGF-1 gene in children with growth disorders. Pediatric endocrinology, diabetes, and metabolism. 2015; 20:136-142.

23. Kanbur NO, Derman O, Kinik E. The relationships between pubertal development, IGF-1 axis, and bone formation in healthy adolescents. Journal of bone and mineral metabolism. 2005; 23:76-83.

24. Sesti G, Mannino GC, Andreozzi F, Greco A, Perticone M, Sciacqua A, Marini MA, Perticone F. A polymorphism at IGF1 locus is associated with carotid intima media thickness and endothelium-dependent vasodilatation. Atherosclerosis. 2014; 232:25-30.

25. Lu L, Wang F, He L, Xue Y, Wang Y, Zhang H, Rong L, Wang M, Zhang Z, Fang Y, Miao H. Interaction Between IGF1 Polymorphisms and the Risk of Acute Lymphoblastic Leukemia in Chinese Children. Cellular physiology and biochemistry. 2015; 36:1346-1358.

26. Nakao M, Hosono S, Ito H, Watanabe M, Mizuno N, Yatabe Y, Yamao K, Ueda R, Tajima K, Tanaka H, Matsuo K. Interaction between IGF-1 polymorphisms and overweight for the risk of pancreatic cancer in Japanese. International journal of molecular epidemiology and genetics. 2011; 2:354-366

27. Burchardt P, Gozdzicka-Jozefiak A, Zurawski J, Nowak W, Durzynska J, Link R, Grotowski T, Siminiak T. Are elevated levels of IGF-1 caused by coronary arteriesoclerosis?: Molecular and clinical analysis. The protein journal. 2010; 29:538-544.

28. Liu NJ, Xiong Q, Wu HH, Li YL, Yang Z, Tao XM, Du YP, $\mathrm{Lu} \mathrm{B}, \mathrm{Hu} \mathrm{RM}$, Wang XC, Wen J. The association analysis polymorphism of CDKAL1 and diabetic retinopathy in Chinese Han population. International journal of ophthalmology. 2016; 9:707-712. 